\title{
Conventional and Molecular Identification of Mycotic Mastitis Caused by Candida in Farm Animals
}

\author{
Doaa D. Khalaf, Mona M. H. Soliman and Asmaa Samy Mansour \\ Department of Microbiology and Immunology, National Research Centre, Egypt \\ *Corresponding author: mona_nrc.micro@yahoo.com
}

\begin{abstract}
\begin{tabular}{llll}
\hline Article History: $19-668$ & Received: $18-S e p-19$ & Revised: $30-S e p-20$ & Accepted: $14-O c t-20$
\end{tabular}
\section{ABSTRACT}

Mycotic mastitis due to Candida is increasing and the identification of Candida species is crucial in choosing the ideal antifungal drugs. Identification of Candida to species level is essential as many non-albicans Candida developed drug resistance against antifungal agents. A total of 138 milk samples $(24,15,46$ and 53 from goats, sheep, buffaloes and cows, respectively) were streaked on plain plates of SDA and incubated. CHROM agar was used to differentiate Candida isolates. Mycological examination revealed the presence of yeast in 8.3, 6.7, 32.6 and $47.2 \%$ milk samples of goats, sheep, buffaloes and cows, respectively. The total isolation percent of yeast in all milk samples was $31.2 \%$. Species identification of Candida in the present work using both CHROM agar and the bio-typing assay (API 20 C AUX) revealed the highest presence of Candida albicans (11.6\%) followed C. glabrata (5.8\%), C. tropicalis (5.1\%) and $C$. krusei (2.9\%). Multiplex PCR gave two different sized PCR products specific for every tested Candida isolates separately. It was concluded that phenotypic and biochemical assays are time-consuming and exposed to misdiagnosis. Whereas multiplex PCR is a genotypic-based technique that permits the identification of species that is difficult to be identified conventionally because of their abnormal morphology or biochemical features and also this assay is simple, easy and time saving so it is recommended to be implemented in clinical laboratories.
\end{abstract}

Key words: Candida, Milk, API 20 C AUX, CHROM agar, PCR.

C2020 IJVS - All Rights Reserved

\section{INTRODUCTION}

Raw milk provides a good environment plus all basic nutrients for the growth of various fungal species (Callon et al. 2007). Those microbes can contaminate raw milk during different processing procedures and in addition to this, it is affected by the animal's physiological state, weather and breeding circumstances (Gulbe and Valdovska 2014).

Bovine mastitis is a disease that involve several causes including the relationship between the host, pathogen and the environment. It is one the most common and infectious manifestation of dairy cows. It is also of economic value in the whole world as it causes $\$ 35$ trillion losses in the global dairy industry (Bradley 2002).

Mastitis is one of the first three pathologies of dairy animals. This pathology may not have clinical manifestation (latent infection, subclinical mastitis), it is the most frequent (95 to $98 \%$ of the cases) and can have an obvious sign (clinical mastitis), the latter only represents 2 to $5 \%$ of the cases. Studies on fungal mastitis are becoming more abundant due to their increasing prevalence. (Akdouche et al. 2018). In mastitis, mammary gland undergoes immune response in which the permeability of conjunctions between milk and blood (milk-blood barrier) are disrupted and this cause physical change in milk (Youssif et al. 2020; Gao et al. 2020; Mingala et al. 2020).

Researchers have revealed that fungal mastitis is increasing, and the most commonly derived pathogens are Candida species which are found normally in the surroundings of dairy cattle (Mbuk et al. 2016). Inadequate antibiotic treatment course can result in outbreaks of fungal mastitis because of the increase of latent infection during the drying-off stage of animals (AL-abidy et al. 2019). Candida species are the most known cause of mycotic infections globally. They are considered the third most common etiology of healthcare-associated infections. Although Candida albicans is the most common species, non-albicans Candida begin to increase remarkably during the last twenty years (Taei et al. 2019).

Identification of Candida species is of great importance in choosing the ideal antifungal drug and as a consequence the treatment process will occur properly as the response against antifungal drugs vary between different Candida species. If complete identification is not

Cite This Article as: Khalaf DD, Soliman MMH and Mansour AS, 2021. Conventional and molecular identification of mycotic mastitis caused by Candida in farm animals. International Journal of Veterinary Science 10(1): 64-68. https://doi.org/10.47278/journal.ijvs/2020.011 
done, random antifungal will be used. The random and abundant use of antifungal drugs for prophylaxis and treatment can develop resistance against some Candida species. Identification of Candida to species level is crucial as many non albicans Candida have lowered susceptibility against antifungal agents (Erbaş et al. 2017).

CHROM agar is a nutritive agar medium with chromogenic substances that can generate different color for each Candida species as light to medium green color for $C$. albicans; dark blue to metallic blue color for $C$. tropicalis finally pink color surrounded by whitish edge for C. krusei. The rest of yeast isolates might generate light to dark mauve or cream colors (e.g., C. glabrata). CHROM agar medium can successfully differentiate $C$. albicans, $C$. tropicalis, and C. krusei (Ozcan et al. 2010). API $20 \mathrm{C}$ AUX is a strip that can be used to perform 20 different biochemical tests sufficient for the identification of a single Candida isolate in addition to this it included a control negative and a control positive. Correct results were achieved when the profile gives the accepted match with the manufacturer's criteria. (Gündeş et al. 2001).

Phenotypic and biochemical assays are widely used in developing countries for species identification (Posteraro et al. 2015). On the other hand, these methods need long time for preparation and are exposed to mistakes (Kathuria et al. 2015). Recently, variety of molecular assays have been utilized for Candida species identification and they regarded accurate and easy to utilize (Liguori et al. 2010). In the last decade, polymerase chain reaction (PCR) is considered as a standard platform in several clinical laboratories even in developing countries due to its reproducibility and affordability. (Arastehfar et al. 2019). Multiplex-PCR was used for amplification of the DNA of Candida. It was used to amplify more than one sample in a single reaction (Hermansyah et al. 2017). Therefore, our goal in the present work was performing quick differentiation of Candida species isolated from milk samples to species level using a quick and easy PCR-based technique that can identify four Candida species ( $C$. albicans, C. glabrata, C. tropicalis and C. krusei). This assay combined two yeast-specific primers and four Candida species-specific primers in a single PCR process giving two different sized bands specific for each species.

\section{MATERIALS AND METHODS}

\section{Yeast Isolates Isolation and Identification}

A total of 138 milk samples $(24,15,46$ and 53 from goats, sheep, buffaloes and cows, respectively) were streaked on plain plates of SDA and were incubated at $30^{\circ} \mathrm{C}$ for $72 \mathrm{~h}$. Pure colonies were subjected to morphological and differential biochemical identification assays (Marinho et al. 2010). Germ-tube test in which yeast isolates were inoculated into $0.5 \mathrm{ml}$ of serum and were incubated at $37^{\circ} \mathrm{C}$ for $2 \mathrm{~h}$. After this period, a drop was examined microscopically for a tube projected with straight walls and without constriction. Germ-tube was positive for $C$. albicans and $C$. dubliniensis, Chlamydoconidia production test on rice agar tween 80 media on which the yeast isolates were streaked on the surface of the medium and a cover slide was added above the streaking lines after three days of incubation at $30^{\circ} \mathrm{C}$. The plates were microscopically examined for the presence and for the arrangement of chlamydospores and carbohydrate assimilation test for maltose, trehalose, xylose, galactose, lactose, sucrose and glucose since all the species of Candida can assimilate this carbohydrate. The plates were incubated at $37^{\circ} \mathrm{C}$ for $3-4$ days. The existence of growth around the carbohydrate disc was considered as assimilation positive for this carbohydrate.

CHROM agar (Cat \# 1382, Condalab, Madrid, Spain) was used to differentiate Candida isolates. It was prepared according to the manufacturer's instructions. Yeast isolates were inoculated by streaking and were incubated at $30^{\circ} \mathrm{C}$ and the judgment of the results was performed by two researchers independently, after 24,48 , and $72 \mathrm{~h}$ of incubation. Fungal isolates were further identified using API 20 C AUX (Cat \# 1006663720, Biomerieux, Marcy l'Etoile, France). It is a readymade 20 biochemical reactions included both control positive (glucose) and control negative in one disposable plastic strip sufficient for the identification of one Candida isolates and the assay was performed according to the manufacturer's instructions.

\section{Molecular Identification of Candida Isolates}

Genomic DNA Extraction was performed with (DNeasy Plant Mini Kit) according to the manufacturer's protocol.

\section{PCR Amplification}

Amplification reaction was done using both universal yeast primers (UNI1 and UNI2) and Candida speciesspecific primers previously described by Carvalho et al. (2007). Multiplex PCR amplification reaction was performed in a $30 \mu \mathrm{l}$ volume consisting of master mix $15 \mu \mathrm{l}$, primers (UNI1 and UNI2, $0.55 \mu \mathrm{M}$ each; C. albicans and C. krusei, $0.15 \mu \mathrm{M}$ each; C. glabrata and C. tropicalis, $0.2 \mu \mathrm{M}$ each), $5 \mu 1$ DNA template and then complete the volume of nuclease free water. PCR was routinely carried out in thermal cycler (model 1105 TECHNE) under the following conditions: Initial DNA denaturation for $10 \mathrm{~min}$ at $94^{\circ} \mathrm{C}$ followed by 40 cycles at $94^{\circ} \mathrm{C}$ for $15 \mathrm{~s}, 55^{\circ} \mathrm{C}$ for $30 \mathrm{~s}$, and $65^{\circ} \mathrm{C}$ for $45 \mathrm{~s}$ and parallel to this control negative reaction was performed in which nuclease free water replaced the DNA template. Electrophoresis was performed for seven $\mathrm{ml}$ from each reaction tube with $2 \%$ agarose. Visualization of DNA bands was implemented by Ethidium bromide staining $(0.5 \mu \mathrm{g} / \mathrm{ml})$ and imaging of the produced bands was implemented using a digital imaging system (White/UV transilluminator) and a 100-bp DNA ladder was used as a ruler to compare between the produced DNA products. Gel analysis was done by lab image software program version 2.7.0 Copyright (C) 1999-2003 Kapelan GmbH.

\section{RESULTS}

A total of 138 milk samples tested for mycological examination revealed the presence of yeast in $31.2 \%$ samples. Being positive for fungal growth in 8.3, 6.7, 32.6 and $47.2 \%$ milk samples of goats, sheep, buffaloes and cows, respectively (Table 1). Species identification of candida in the present work as shown in Table 2 that indicated the presence of Candida albicans in $11.6 \%$ while it was $2.9 \%$ positive for $C$. krusei whereas it was $5.8 \%$ of for C. glabrata and finally it was $5.1 \%$ for C. tropicalis. 
Table 1: Incidence of yeast isolates in the examined milk samples

\begin{tabular}{lcc}
\hline Milk samples & \multicolumn{2}{c}{ Yeast positive samples } \\
\cline { 2 - 3 } & No. & $\%$ \\
\hline Goat milk $(\mathrm{n}=24)$ & 2 & 8.3 \\
Sheep milk $(\mathrm{n}=15)$ & 1 & 6.7 \\
Buffalo milk $(\mathrm{n}=46)$ & 15 & 32.6 \\
Cow milk $(\mathrm{n}=53)$ & 25 & 47.2 \\
Total $(\mathrm{n}=138)$ & 43 & 31.2 \\
\hline
\end{tabular}

Table 2: Results of identification using CHROM agar

\begin{tabular}{lcccc}
\hline \multirow{2}{*}{ Species no. } & \multicolumn{4}{c}{ Colony colors using CHROM agar } \\
\cline { 2 - 5 } & Green & Pink & White & Blue \\
\hline Goat milk $(\mathrm{n}=24)$ & 1 & - & - & - \\
Sheep milk $(\mathrm{n}=15)$ & 1 & - & - & - \\
Buffalo milk $(\mathrm{n}=46)$ & 5 & 2 & 2 & 3 \\
Cow milk $(\mathrm{n}=53)$ & 9 & 2 & 6 & 4 \\
Total $(\mathrm{n}=138)$ & $16(11.6 \%)$ & $4(2.9 \%)$ & $8(5.8 \%)$ & $7(5.1 \%)$ \\
\hline
\end{tabular}

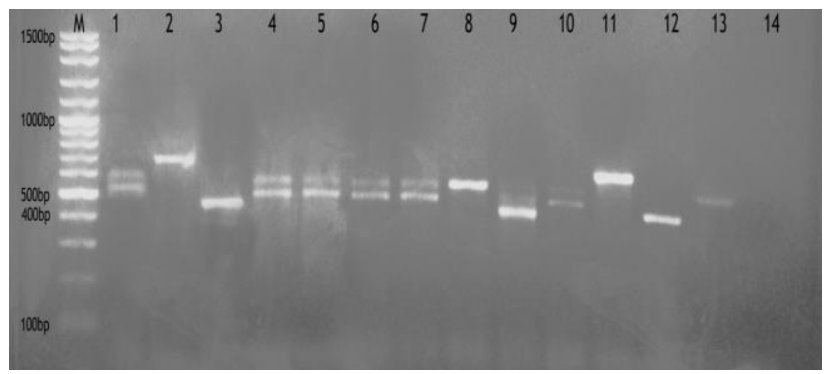

Fig. 1: Amplified PCR products (agarose gel electrophoresis) of different Candida isolates. (Lane M: 100-bp DNA ladder, Lanes from 1-13 are the tested isolates and Lane 14: negative control).

Accurate identifications were achieved for 35 Candida isolates with CHROM agar medium and API 20C Aux in the present work. Candida isolates identified conventionally were tested using multiplex PCR. Results of multiplex PCR in Fig. 1 showing the agarose gel electrophoresis pattern of thirteen Candida isolates. $C$. tropicalis, C. glabrata, C. albicans and C. krusei were identified in samples at molecular weight 500 and 580, 890, 440 and 570 base pair (bp), respectively.

\section{DISCUSSION}

Mastitis is one of the most dominant disease in dairy animals. The symptoms of mastitis include different abnormalities as the watery consistency of milk, clots, flakes, or pus in mastitic milk (Firyal et al. 2019; Saleem et al. 2019; Rawat et al. 2020). The incidence of mycotic mastitis is generally very low and the incidence of fungal mastitis in the United States ranged from (2\%-7\%) and those rates can be higher in tropical regions. But the prevalence of mycotic mastitis has remarkably increased during the past decade. Mycotic mastitis is often caused by Candida species (Sonmez and Erbas 2017).

The present study revealed the presence of yeast in $8.3 \%$ in goat milk samples, $6.7 \%$ in sheep milk samples, $32.6 \%$ in buffalo milk samples and finally $47.2 \%$ in cow milk samples while the total isolation percent of yeast in all milk samples was $31.2 \%$. Those results found to be much similar to those obtained by dos Santos and Marin (2005) as fungi were isolated from $32 \%$ of the tested samples and Candida species represents $17.3 \%$ from them. Our results were higher than those obtained by Krukowski et al. (2001) as they assured that the isolation percent of fungi from the tested milk specimen in the Lublin region in Poland was 9.6\%. Moreover, Dworecka-Kaszak et al. (2012) isolated fungi from $14 \%$ of tested samples and they isolated Candida species with other microbes species from $39 \%$ but Candida species was isolated alone from $11 \%$ of these cases also similar results were achieved by Costa et al. (1993) in Brazil by $12.07 \%$. Lower isolation rates were recovered by Awad et al. (1980) in Egypt with 6.1\% while the lowest isolation rates with $1.3 \%$ in Denmark by Aalbek et al. (1994). However, Krukowski et al. (2020) isolated yeasts from $(1 \%)$ of the tested specimens and this is very low isolation rate in compared with our study and the other studies as well and they derived Candida species from (91.6\% of positive yeast specimens). dos Santos and Marin (2005) stated that in surveys, fungal isolation percentage implemented in many countries differs considerably (Imran et al. 2020).

Species identification of candida in the present work as shown in Table 2 assured the presence of Candida albicans in (11.6\%), C. krusei (2.9\%), C. glabrata (5.8\%) and $C$. tropicalis $(5.1 \%)$. Those results found to be much similar to those obtained by Spanamberg et al. (2014) as they isolated fungi $C$. albicans, C. glabrata, C. tropicalis and Pichia guilliermondii from both normal and mastitic ewe milk samples. In the present investigation, $C$. albicans was the most frequently isolated species (11.6\%), $C$. glabrata (5.8\%), C. tropicalis $(5.1 \%)$ and finally C. krusei $(2.9 \%)$ and our results are in agreement with those obtained by Costa et al. (1993) as they isolated mostly C. albicans but different results were obtained by Dworecka-Kaszak et al. (2012) as they mostly isolated C. parapsilosis (25 strains), C. krusei (15 strains) and only one C. albicans strain and also Krukowski et al. (2001) assured that in Poland, C. kefyr, C. cirferi, and C. krusei were the most abundantly isolated Candida species.

Accurate identifications with CHROM agar medium was achieved in the present work. However, those strains of $C$. albicans and non- C. albicans, sometimes did not only fail to produce the predicted colors, but sometimes the produced colors were also false. In particular, with CHROM agar medium C. tropicalis and C. krusei can be identified correctly, while the rest of the yeast species were difficult to be identified correctly. A laboratory technique that is performed within $72 \mathrm{~h}$ for preliminary identification of C. albicans, C. tropicalis, and C. krusei is of doubtful value. Chromogenic medium could not be used as a sole identification tool as biochemical identification must be performed to avoid incorrect identification accordingly, CHROM agar medium could be considered as a primary isolation medium and cannot be used alone in identification of Candida species (Ozcan et al. 2010).

The API 20C AUX, a manual assay, needs great accuracy during test performing, experience in the judgment of turbidity level, and frequently, long incubation periods, but it is dependable, simple to use and cheap (Liguori et al. 2010).

Precise identification with API 20C Aux was accomplished in the present study. Several studies on the API 20C Aux system found that it has 88-99\% accuracy. Our results were similar with those obtained by Fenn et al. (1994) as they obtained 99\% accurate identification of their yeast isolates using API 20C Aux while Davey et al. (1995) achieved $88 \%$ correct identification and lower appropriate 
identifications $(87 \%)$ were obtained by Gündes et al. (2001) and this variation may attribute to differences in species distribution. Incompletely identified isolates need additional tests to complete their identification.

Due to the lack of financial resources in developing countries for high-priced and accurate means of identification, such as MALDI-TOF MS and Sanger sequencing. Multiplex PCR assay is cheaper alternative with good outcome and can be implemented in large-scale epidemiological studies (Arastehfar et al. 2019).

Simple, easy and time saving method for identification of Candida species using both universal yeast primers (UNI1 and UNI2) and Candida species-specific primers. Yeast universal primers enable a broad detection ability for yeast isolates whereas species-specific primers could identify species of Candida in a sole PCR tube.

The combination of UNI1 and UNI2 with the speciesspecific primers of Candida implemented in this study yielded specific band patterns, enabling simple and rapid identification of the questionable Candida species. However, this technique is a genotypic-based method that can identify Candida species which is difficult to be differentiated by conventional methods and also it can identify mixed infections. Furthermore, this multiplex technique can be adopted in clinical laboratories as it is relatively cheap since it only requires the basic DNA isolation reagents and PCR components and it does not need neither restriction enzymes nor DNA probes.

Candida isolates were tested using multiplex PCR reaction in the current work and C. tropicalis, C. glabrata, C. albicans and C. krusei were identified successfully using the multiplex PCR and the produced PCR product bands shown in Fig. 1 were similar to the results obtained by (Carvalho et al. 2007). The multiplex Candida PCR had exhibited good sensitivity and specificity on clinical specimens of high-risk individuals for direct recognition of Candida species in whole blood specimens. Multiplex PCR technique can serve contribute rapid and precise diagnosis of candidiasis. (Fuchs et al. 2019) and also (Susilawati et al. 2019) assured that multiplex PCR assay is a quick alternative in discriminating Candida species due to its high specificity and high sensitivity.

\section{Conclusion}

Conventional ways used in Candida species identification are less effective and have a lot of drawbacks and Multiplex PCR performed in the present work enables us to identify accurately Candida species even those with abnormal characteristics and this technique should be executed in clinical laboratories.

\section{Author's Contribution}

All authors shared in study design, data gathering, executing the practical part, results analysis and shared in writing of the manuscript.

\section{REFERENCES}

Aalbek B, Stenderup J, Jensen HE, Valbak J, Nylin B and Huda A, 1994. Mycotic and algal bovine mastitis in Denmark. Acta Pathologica, Microbiologica et Immunologica 102: 451-456. https://doi.org/10.1111/j.1699-0463.1994.tb04898.x
Akdouche L, Aissi M and Saadi A, 2018. Prevalence and identification of yeasts responsible for mastitis in dairy cattle farms in the SidiLahcene Region in the Wilaya of Sidi Bel abbes- Algeria. Advances in Dairy Research Journal 6: 206. https://doi.org/10.4172/2329-888X.100020.

AL-abidy HFHA, Khudaier BY and Al-attraqchi AA, 2019. Conventional and molecular detection of Candida albicans and Candida parapasilosis isolated from bovine mastitis in Basrah-Iraq. Biochemical and Cellular Archives 19: 32853289. https://doi.org/10.35124/bca.2019.19.2.3285

Arastehfar A, Fang W, Pan W, Lackner M, Liao W, Badiee P, Zomorodian $\mathrm{K}$, Badali $\mathrm{H}$, Hagen $\mathrm{F}$, Lass-Flörl $\mathrm{C}$ and Boekhout T, 2019. Yeast panel multiplex PCR for identification of clinically important yeast species: stepwise diagnostic strategy, useful for developing countries. Diagnostic Microbiology and Infectious Disease 93: 112119. https://doi.org/10.1016/j.diagmicrobio.2018.09.007

Awad FI, El-Molla A, Fayed A, Abd-El-Halim M and Refai M, 1980. Studies on mycotic mastitis in Egypt. Journal of the Egyptian Veterinary Medical Association 40: 35-41.

Bradley AJ, 2002. Bovine mastitis: an evolving disease. Veterinary Journal 164: 116-128. https://doi.org/10.1053/ tvjl.2002.0724

Callon C, Duthoit F, Delbès C, Ferrand M, Le Frileux Y, De Crémoux R and Montel MC, 2007. Stability of microbial communities in goat milk during a lactation year: molecular approaches. Systematic and Applied Microbiology 30: 547560. https://doi.org/10.1016/j.syapm.2007.05.004

Carvalho A, Costa-De-Oliveira S, Martins ML, Pina-Vaz C, Rodrigues AG, Ludovico P and Rodrigues F, 2007. Multiplex PCR identification of eight clinically relevant Candida species. Medical Mycology 45: 619-627. https://doi.org/10.1080/13693780701501787

Costa EO, Gandra CR, Pires MF, Coutinho SD, Castilho W and Teixeira CM, 1993. Survey of bovine mycotic mastitis in dairy herds in the State of São Paulo, Brazil. Mycopathologia 124: 13-17. https://doi.org/10.1007/bf01103051

Davey KG, Chant PM, Downer CS, Campbell CK and Warnock DW, 1995. Evaluation of the Auxacolor system, a new method of clinical yeast identification. Journal of Clinical Pathology 48: 807-809. https://doi.org/10.1136/jcp.48.9.807

dos Santos RD and Marin JM, 2005. Isolation of Candida spp. from mastitic bovine milk in Brazil. Mycopathologia 159: 251-253. https://doi.org/10.1007/s11046-004-2229-2

Dworecka-Kaszak B, Krutkiewicz A, Szopa D, Kleczkowski M and Biegańska M, 2012. High prevalence of Candida yeast in milk samples from cows suffering from mastitis in Poland. The scientific World Journal Volume 2012: Article \# 196347. https://doi.org/10.1100/2012/196347

Erbaş G, Parin U, Kirkan Ş, Türkyilmaz S, Savaşan S, Yüksel HT and Öztürk S, 2017. Antifungal susceptibilities and identification of Candida species by using maldi-tof microbial identification system from cervicovaginal samples. International Journal of Research in Medical Sciences 5: 5117-5120. https://doi.org/10.18203/2320 6012.ijrms20175429

Fenn JP, Segal H, Barland B, Denton D, Whisenant J, Chun H, Christofferson K, Hamilton L and Carroll K, 1994 Comparison of updated vitek yeast biochemical card and API 20C yeast identification systems. Journal of Clinical Microbiology 32: 1184-1187. https://doi.org/10.1128/jcm. 32.5.1184-1187.1994

Firyal S, Tanveer S, Awan AR, Tayyab M, Wasim M, Nawaz M, Sattar H, Nawaz S, Saeed S and Ali MM, 2019. Association of bovine tumor necrosis factor alpha gene polymorphism with mastitis in Nili Ravi buffaloes. Pakistan Veterinary Journal 39: 128-131. http://doi.org/10.29261/pakvetj/2018. 121.

Fuchs S, Lass-Flörl C and Posch W, 2019. Diagnostic Performance of a novel multiplex PCR assay for candidemia 
among ICU Patients. Journal of Fungi 5: 86. https://doi.org/ $\underline{10.3390 / \text { jof } 5030086}$

Gao J, Liu YC, Wang Y, Li H, Wang XM, Wu Y, Zhang DR, Gao $S$ and Qi ZL, 2020. Impact of yeast and lactic acid bacteria on mastitis and milk microbiota composition of dairy cows. AMB Express 10: 22. https://doi.org/10.1186/s13568-020$\underline{0953-8}$

Gulbe G and Valdovska A, 2014. Diversity of microscopic fungi in the raw milk from Latvian organic farms. Proceedings of the Latvia University of Agriculture 31: 46-53. https://doi.org/10.2478/plua-2014-0006

Gündeş SG, Gulenc S and Bingol R, 2001. Comparative performance of fungichrom i, candifast and API 20C aux systems in the identification of clinically significant yeasts. Journal of Medical Microbiology 50: 1105-1110. https://doi.org/10.1099/0022-1317-50-12-1105

Hermansyah, Adhiyanti N, Julinar, Rahadiyanto KY and Susilawati, 2017. Identification of Candida species by assimilation and multiplex-PCR methods. Journal of Chemical Technology and Metallurgy 52: 1070-1078.

Imran M, Cao S, Wan SF, Chen Z, Saleemi MK, Wang N, Naseem MN and Munawar J, 2020. Mycotoxins - a global one health concern: A review. Agrobiological Records 2: 1-16. https://doi.org/10.47278/journal.abr/2020.008

Kathuria S, Singh PK, Sharma C, Prakash A, Masih A, Kumar A, Meis JF and Chowdhary A, 2015. Multidrug-resistant Candida auris misidentified as Candida haemulonii: characterization by matrixassisted laser desorption ionization-time of flight mass spectrometry and DNA sequencing and its antifungal susceptibility pro file variability by vitek 2, CLSI broth microdilution, and Etest method. Journal of Clinical Microbiology 53: 1823-1830. https://doi.org/10.1128/jcm.00367-15

Krukowski H, Tietze M, Majewski T and Różański P, 2001. Survey of yeast mastitis in dairy herds of small-type farms in the Lublin region, Poland. Mycopathologia 150: 5-7. https://doi.org/10.1023/a:1011047829414

Krukowski H, Lassa H, Zastempowska E, Smulski S and BisWencel H, 2020. Etiological agents of bovine mastitis in Poland. Medycyna Weterynaryjna-Veterinary MedicineScience and Practice 76: 221-225. https://doi.org/10.21521/ $\underline{\text { mw. } 6339}$

Liguori G, Gallé F, Lucariello A, Di Onofrio V, Albano L, Mazzarella G, D'Amora M and Rossano F, 2010. Comparison between multiplex PCR and phenotypic systems for Candida spp. identification. New Microbiologica 33: 63-67.

Liguori ${ }^{2}$ G, Di Onofrio V, Gallé F, Lucariello A, Albano L, Catania MR and Guida M, 2010. Candida albicans identification: comparison among nine phenotypic systems and a multiplex PCR. Journal of Preventive Medicine and Hygiene 51: 121-4. https://doi.org/10.15167/2421-4248/ jpmh2010.51.3.225

Marinho SA, Teixeira AB, Santos OS, Cazanova RF, Ferreira CAS, Cherubini K and Oliveira SDD, 2010. Identification of Candida spp. by phenotypic tests and PCR. Brazilian Journal of Microbiology 41: 286-294. https://doi.org/10.1590/ s1517-83822010000200004

Mbuk EU, Kwaga JKP, Bale JOO and Umoh JU, 2016. Molecular identification of yeasts associated with raw cow milk from peri-urban farms in Kaduna State, Nigeria. Journal of Yeast and Fungal Research 7: 39-46. https://doi.org/10.5897/ jyfr2016.0172

Mingala CN, Wy AMP, Cruz DGD, Ermitanio ED, Gaban PBV and Castro DFP, 2020. Alpha-2-Macroglobulin gene polymorphism in water buffaloes (Bubalus bubalis) with subclinical mastitis. International Journal of Veterinary Science 9: 116-120.

Ozcan K, Ilkit M, Ates A, Turac-Bicer A and Demirhindi H, 2010. Performance of Chromogenic Candida agar and CHROMagar Candida in recovery and presumptive identification of monofungal and polyfungal vaginal isolates. Medical Mycology 48: 29-34. https://doi.org/ $\underline{10.3109 / 13693780802713224}$

Posteraro B, Efremov L, Leoncini E, Amore R, Posteraro P, Ricciardi W and Sanguinetti M, 2015. Are the conventional commercial yeast identification methods still helpful in the era of new clinical microbiology diagnostics? A metaanalysis of their accuracy. Journal of Clinical Microbiology 53:2439-50. https://doi.org/10.1128/jcm.00802-15

Rawat S, Verma H and Jaiswal V, 2020. Isolation of Candida Spp. from mastitis milk. International Journal of Livestock Research 10: 185-187. https://doi.org/10.5455/ijlr. 20191114081520

Saleem MI, Saqib M, Khan MS, Muhammad G and Rehman SU, 2019. Epidemiological study of mastitis in three different strains of beetal goat in selected districts of Punjab, Pakistan.

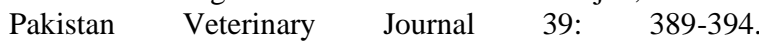
http://doi.org/10.29261/pakvetj/2018.118

Sonmez M and Erbas G, 2017. Isolation and identification of Candida spp. from mastitis cattle milk and determination of antifungal susceptibilities. International Journal of Veterinary Science 6: 104-107.

Spanamberg A, Fraga CF, Ferreiro L, Aguinsky MS, Sanches EMC, Roehe C, Lautert C and Santurio JM, 2014. Yeasts in the Raw Ewe's Milk. Acta Scientiae Veterinariae 42: 1236.

Susilawati, Rahadiyanto KY, Theodorus and Hermansyah H, 2019. The use of multiplex-PCR method in identification of Candida species from vaginal candidiasis patients. Biodiversitas Journal of Biological Diversity 20: 3063-3069. https://doi.org/10.13057/biodiv/d201040

Taei M, Chadeganipour M and Mohammadi R, 2019. An alarming rise of non-albicans Candida species and uncommon yeasts in the clinical samples; a combination of various molecular techniques for identification of etiologic agents. BMC Research Notes 12: 779 https://doi.org/10.1186/s13104-019-4811-1

Youssif NH, Hafiz NM, Halawa MA, Aziz HM and Saad MF, 2020. Impact of subclinical mastitis on milk quality in different seasons. International Journal of Veterinary Science 9: 313-316. 